\title{
Towards the Path of "Health in All Policies" in Germany: Proposal for a Policy Paper
}

\author{
Mandl Stangl J* \\ Stadtbergen Leitershofen, Germany
}

*Corresponding author: Jorge Mandl Stangl, Stadtbergen Leitershofen, Germany, E-mail: jorge_mandl@yahoo.com

\section{Conceptual Paper}

Volume 4 Issue 6

Received Date: November 18, 2021

Published Date: December 03, 2021

DOI: $10.23880 /$ jqhe-16000248

\section{Abstract}

The idea that it is possible to improve the health of citizens through integrated strategies with a "Health in all Policies" approach has been advocated in Germany mainly from an academic point of view and not from affiliations or competencies to strengthen political cooperation in, by and for health and well-being. Our central proposal suggests a political route for consideration by the federal government. We conclude with a series of reflections on the feasibility of the ideas presented.

Keywords: Health in All Policies; Policy Process; Intersectorality; Health Promotion; Germany

Abbreviations: EPHO: Essential Public Health Operations.

\section{Introduction}

The COVID 19 pandemic has demonstrated once again that health outcomes are moving beyond the realm of service delivery alone and shifting public and private governance towards an inclusive agenda in which the social determinants of health and the interaction between sectors and society as a whole are an important part of the social policy mix, whose central aim is to provide sustainable, equitable and caring solutions to people's needs and quality of life choices related to the right to their health, while contributing to sustainable development [1].

In line with this approach, the Eighth World Conference on Health Promotion, held in Helsinki in 2013 [2], highlighted the need to integrate health into the policy process to ensure that other government goals are met and to influence nonhealth but health-related factors such as poverty, access to water and sanitation, security, and social and economic development. The central objective of the conference was to advance the "health in all policies" approach.

In 2020, the German government published its new global health strategy [3] after three years of consultations involving several ministries, academia, youth, civil society, private sector organisations and an international advisory board. In this line of work, since early 2019, the Zukunftsforum Public Health has been developing a technical roadmap, whose most recent document [4] addresses the qualitative transformation of the processes of integrating all aspects related to optimal health system performance through joint actions and aims to show how to implement "Health in all Policies“ through ten priority task areas („EPHO“).

Understanding that this approach was conceived to promote political cooperation in health and welfare as a bottom-up planning tool, and that its implementation must be inseparable from a national programme, in this manuscript we want to propose a political roadmap for the next federal government and its consolidation in the German Länder, districts and municipalities.

We consider it appropriate to divide the content of the paper under several headings: We start from a conceptualisation of health in all policies as a management tool to improve the quality of strong public policy making. Secondly, we develop our central proposal for the decisionmaking process, as well as the convergence in this model with the Zukunftsforum's Public Health proposal in the short, medium and long term. We conclude with a series 
of reflections on the validity of the ideas presented, thus constituting a renewed call for debate and public consultation by different actors.

\section{Conceptual Considerations}

We conceptualise health in all policy sectors as a management model characterised by a sequence of integrated and sustainable public policies that are the product of multisectoral and transdisciplinary processes of social mediation to ensure that all members of society have fair and equitable opportunities to participate in decisions that enable changes in their quality of life and health; through a significant change in the forms of interaction between political actors, social groups or networks and institutions, within a shared historical-cultural environment in whose dynamics and interrelationship policy initiatives in all sectors of government have a positive impact while contributing to the achievement of fundamental objectives in other sectors and policy domains [5].

There are general policy situations where the application of the model is considered useful: a) complex health problems; this refers to population health, equity and health system challenges that require cross-sectoral policy solutions; b) government policies with high health impact; these are proposals from non-health sectors that could have a significant impact on health or health equity; c) government priority affecting many sectors; this policy situation can occur when the government has a high priority objective that affects the health sector, but its resolution requires proactive engagement with other sectors [6].

In Germany, „Health in all policies“ approaches have so far been applied only selectively and on a project-by-project basis, and are mainly limited to municipalities or districts $[7,8]$. To address the above-mentioned problems at the national level with the proposed model, a number of prerequisites are necessary: a) an overall political coordination, both between the different supra-regional, regional and local levels and between the different actors, which helps to strengthen political and functional decentralisation as a principle of administrative organisation; b) situational leadership - political and executive - to achieve an adequate horizontal linkage as well as a vertical linkage of the levels within the sectors of the organisation. This implies the need to reorganise concurrent responsibilities between federal, state and local governments, including private institutions and civil society movements; c) greater formal or informal participation of citizens or community organisations in decisions on planning, strategies, public policy management and control of development initiatives that directly or indirectly affect their health and quality of life, to achieve an equitable distribution of power, money and resources; d) Integrate the objectives of different organisations with broader societal objectives in the development of a public health strategy that focuses on reducing inequalities, social cohesion, building the resilience of the next generations, reducing unsustainable production and consumption and combating climate change; this would ensure greater policy coherence and the achievement of mutually beneficial and mutually supportive objectives; e) institutionalise participatory strategic planning as a result of an agreement between society and governments to mitigate welfare inequalities and; f) standardise criteria for monitoring and evaluation of the context by all actors involved so that the model can adapt to changing political/economic/social realities and demonstrate that the desired outcomes are the product of an inter-institutional organisational process.

\section{A Policy Pathway For Health in All Policies}

\section{Structuring Phase}

We have conceptualised the proposal as a planned change process that represents an opportunity for a comprehensive transformation of the system, based on innovation from the current leadership style towards a large public policy network. This process will require significant work to foster a shared vision among the different actors, a concerted strategy and a common action plan for collective decision-making, as well as monitoring and feedback for consolidation in 2030.

To begin the political journey, we propose two lines of action: The first one - top-down - aims to strengthen leadership at supra-regional and national levels. In the first 180 days, the government should create and implement an administrative body in charge of ensuring the integration of public health as a general element related to the social determinants of health, the focus on equity as a state responsibility, and wellbeing as a legal standard to be agreed between administrations and relevant actors in society.

This working group, chaired by the Bundeskanzler and coordinated by a delegate from his office with great capacity for concertation, must have a multidisciplinary and multisectoral team, temporary, with equal voice and vote, and whose actors will not have substitutes for the duration of their mandate. It will consist of:

- One authorised spokesperson for each of the existing ministries;

- five authorised spokespersons appointed by the National Assembly, representing the majority political groups;

- one authorised spokesperson for each of the prime ministers of the Länder;

- one authorised spokesperson representing the mayors;

- an authorised spokesperson for the universities

- an authorised spokesperson for the German Academy of 
Sciences Leopoldina;

- an authorised spokesperson of the Robert Koch Institute

- a spokesperson authorised by the respective professional associations;

- a spokesperson authorised by NGOs working in the field;

- an authorised spokesperson for the organised communities in each Länder;

- an authorised spokesperson for the private sector

- a representative of the European Union Parliamentary Group; and

- a representative of the World Health Organisation in Germany.

The team will focus on negotiating public sector commitments and defining strategies to create a structure to strengthen the process. In addition, it must establish two cross-cutting lines of work: the first requires formalising the proposal in the short term through legal support; the second requires elaborating a bottom-up operational plan with a medium- and long-term perspective, allowing for its mandate and projection in the national territory.

The objectives to be achieved should always aim to develop the maximum health potential, promote health gains for the entire population, focus on the social determinants of health inequalities and, ultimately, achieve policy coherence to ensure progress towards sustainable development [9].

At the end of the 180 days, the working group will complete its tasks and propose the creation of a coordinating society that will thereafter oversee successive work streams through formal structures such as government councils, intersectoral cabinets, cabinet secretariats and commissions, parliamentary commissions, interdepartmental committees, interdepartmental units $[10,11]$ and ensure the pursuit of health and equity as a goal of collective well-being through the participation of all sectors of government and society as a whole.

These structures will be replicated in the administrative regions - at state and local levels - adapted to the realities of each government agency. Functionality will depend on the alignment of associative spaces - cluster-like - according to their internal grouping, knowledge dynamics, articulation and mutual functioning in inter-organisational cooperation.

The second line of action requires focusing on the creation of governance networks with the fundamental objective of contributing to the construction of a social order based on collective agreements and a shared mission to achieve community and institutional objectives. These are described as ,joint governance" methods to achieve national policy coherence and "whole-of-society" methods to build coalitions with different actors [12,13]. It consists of two sub-moments:

- Sub-Moment A: A further 180 days will be needed for consolidation, during which time the following actions should be implemented:

$>$ Establish a formal governance structure (EPHO $6,8)$ : The concept of governance for health and wellbeing refers to the structures and processes through which political and social actors engage in exchange, coordination, monitoring and decision-making practices aimed at solving problems, including reducing health inequalities or creating opportunities for the community in the pursuit of health as an integral part of well-being. The network-based governance structure is underpinned by a commitment to solidarity and shared responsibility between state and society for sustainable and healthy development, the functioning of which is embodied in an agenda [14].

This agenda, whose central purpose is to lead to incremental changes in practice through dialogue, experimentation and innovation, will include, at a minimum: a) a political vision underpinned by technocratic planning; b) a strategy focused on prioritising human rights; c) the identification of the impact of social determinants through situation analysis and impactassessments across government and communities; d) creative and results-oriented solutions and; e) the establishment of an evaluation methodology with continuous monitoring.

The above processes must lead to changes in other policy areas outside the health sector, whether in their rationale, content, financing and implementation or legal basis, so that a positive impact on health or health determinants is achieved, while at the same time impacting on health equity [15].

This is achieved through five types of interaction: a) governance through citizen participation; b) through reciprocity; c) through a mix of regulation and argumentation; d) through external consultants and expert panels and; e) through adaptive policies [16],

> Institutional and technical capacity building (EPHO 7): The rapidly changing environment and the increasing need for joint strategies require new capacities to adapt to change. This would be achieved by: a) training professionals to acquire the necessary knowledge and skills; b) building institutional capacity; c) organising research capacity and teaching and research collaboration across sectors; d) increasing the potential for teamwork within and between ministries and; e) strengthening community knowledge. Skills can be acquired through training methods such as seminars 
and courses, but other methods of disseminating knowledge and skills, including online approaches, should also be explored.

Achieving the above objectives requires close links between universities, colleges, schools of public health or the public health/health sciences professions and public health academies as venues for research and/or teaching and their integration with other professional activities. Most important, however, is the linking of these competencies with professional practice or applied research at federal, state and local levels.

To this end, a group of experts - which we will call "change entrepreneurs" - will be formed as needed to support officials, political leaders, parliamentarians, nongovernmental organisations and communities in the future phases of "start-up", " maintenance" and in support of „sustainability“ [17-19].

$>$ Establish mediation and monitoring mechanisms that can provide a window on health in all policies related to citizens' quality of life (EPHO 1-2-3, 9-10): It is essential that policy makers have a reliable and clear picture of how health is distributed in a given population, identify possible synergies in the implementation of tasks, develop common procedures, and know which indicators contribute to or reduce the opportunities and risks of being healthy. This requires a national public health surveillance approach that also includes the state and local levels and integrates data from other policy areas in a timely manner in order to set priorities and plan participatory actions, thus creating a solid basis for the engagement of different actors. This includes health situation analysis, developed by Ministry of Health staff to analyse and explain the state of health and its social determinants affecting the population, and health impact analysis [20] to evaluate a policy, programme or project in terms of its potential impact on population health.

- Sub-moment B: This is about building social capital at the local level, strengthening associativity and citizen mobilisation, with the aim of ensuring citizen participation in relation to broader political, social and cultural changes around health and well-being, especially of vulnerable groups. The closer people are to the policy spheres, such as at community level, the better and quicker it is known that Health in All Policies is being implemented, and the more often there will also be greater political will for it.

We will consider four key elements: Community ownership, collective efficiency, community capacity and community competence [21]. This requires a continuous, transparent and ongoing process to: a) empower families as producers of well-being rather than mere recipients of services; b) recognise and make visible community potential, involve families, recognise their participation in decision-making and encourage decision-makers to engage in problem-solving; c) empower communities to take control of their future, create tangible resources to reduce social inequalities and create social order through collective agreements; d) create channels of trust and communication in relationships between individuals in a household and government organisations to find solutions to problems caused by the social determinants of health; e) link different groups or networks to achieve a common goal or set of goals; f) ensure interaction between citizens and the exercise of citizens' rights throughout the process; and g) facilitate greater understanding and influence for decision-makers at the community level.

The success of this process, which is fundamental to health promotion and disease prevention (EPHO 4-5), relies on the development of very active policies aimed at building strategic alliances to develop an integration of groups characterised by a balance between solidarity; shared responsibility; social justice based on similar development opportunities for those most in need; the individual, political and civil rights of communities to influence the social determinants of health that strengthen these rights at the local level; and the ethical-political commitment to their duties in the exercise of a true democracy.

This requires a continuous, transparent and sustained process - from the ground up - that goes beyond 180 days, and the Federal Ministry for Family Affairs would have a crucial role to play.

\section{Implementation Phase}

This involves the implementation of action plans at the local level, as a result of a major agreement between the three levels of government, in a kind of meeting place for health and well-being, through three stages:

Stage I (extension) which covers a period of three and a half years and includes a number of municipalities selected on the basis of their high rates of unmet basic needs, as demonstrated by the respective situation and health impact analyses; in addition to the following criteria:

- Political will of the mayor and the municipal council to contribute to the social transformation of communities through deliberative mechanisms;

- willingness towards equity, cohesion, inclusion, health equity and social justice in diversity;

- $\quad$ capacity and potential of citizens and administration to create shared meeting spaces that strengthen community 
identity towards health/wellness and develop shared solutions with their own technologies;

- local infrastructure and presence of enabling factors to achieve sustainable results in relation to the changes envisaged, such as: strategic partnerships, strong norms, health promotion frameworks and the cultural tradition of citizen participation.

The action plans are designed in an open and creative way, agreed between the municipality and citizens - approved in an Open Council - and follow a roadmap defined according to the municipal reality. They will consist of a series of productive projects, with a methodology used in the Healthy Cities Movement [22].

The projects will have the following characteristics: a) they must be elaborated and implemented by citizens, accompanied by technicians from the public administration; b) concrete objectives and visible results, covering at least two areas related to local development (e.g., nutrition workers' health - industry); c) monitoring and evaluation are carried out during the project by a permanent team in the city or community; the sustainability of the results must be the responsibility of the families; d) results and rewards must benefit all partners and; e) methodological support is provided by the coordinating body through the „entrepreneurs of change“.

To secure funding, three premises need to be highlighted: firstly, the implementation of legal mechanisms as a way to promote complementarity and financial sustainability. Secondly, the promotion of opportunities for intersectoral action, this is crucial to change the culture and discourse around health criteria in the offices of a variety of government agencies that have not previously considered health as part of the agenda; and finally, the creation of a range of possible funding sources: a) direct health-oriented funding at all political levels; b) pooled or blended budgets; c) delegated funding; d) independent public funding; e) tax incentives; f) in-kind funding [23].

For a timely feedback of priorities and objectives, it is proposed to carry out an analysis of the health situation and an analysis of the impact on health, in the medium term (1-3 years) and in the long term (5-8 years). For this evaluation of the plan and especially of the productive projects, the following considerations are raised:

- If the priority is to change structural social determinants - strengthening of social capital, greater community empowerment, improvement of social and material conditions - a large part of the impact would be on the mechanisms of redistribution of power; it would therefore be relevant to analyse whether the content of the interventions contemplates processes of social reform or transformation.

- If the priority is on living and working conditions, psychosocial factors and habits or lifestyles, a large part of the impact would be aimed at reducing the exposure and vulnerability of the population.

- If the priority were the impact of social protection, these interventions would focus mainly on service provision and access to services.

- If the priority were the health gradient, i.e. the relationship between socio-economic position and health in the population as a whole, the focus would be on addressing health inequalities. In this approach, tackling health inequalities becomes the goal of improving health for all.

Stage II (scaling up): This phase involves the deepening of the process in all municipalities in the 16 Länder over a period of 5 years. This step involves the formation of sustainable development networks that: a) strengthen the integration process for social change that generates mutual benefits between health and other policies between municipalities, Länder and ministries; b) open a horizontal and vertical communication channel between initiatives, thus promoting competitiveness; c) create a channel for the exchange of experiences; d) obtain and offer technical and political support at national and international level.

Stage III (consolidation): The process should be $100 \%$ in line with the Sustainable Development Goals in Germany by the end of 2030. One of the main challenges of this phase is the evaluation of the whole process; for this we propose an external audit by international experts over a period of 6 months, using a methodology that includes the following indicators 1) political potential; 2) policy development; 3) coherence of the scaling-up process and the way policies are implemented in the target population, especially in vulnerable communities; 4) conditions and practices resulting from the implementation of policies that benefit the health of the population and; 5) reduction or elimination of risk, improvement of health or well-being of the population.

From the publicising of these experiences, a management model could be generated for other Countries.

\section{Some Reflections as Conclusion}

The Paper presents a programmatic proposal for the urgent implementation of "health in all policies" in Germany, and the formulation of a management model for the promotion of health and well-being in the long term. It is also a political transition alternative, between an outgoing government that initiated and developed this approach, and an incoming government that puts at the centre of its 
action new strategies, governance and working methods whose elaboration, deliberation and negotiation must begin immediately and which must necessarily be approached in a thoughtful and calm manner from a State perspective.

We recognise that these changes will not be easy to implement and that the solutions go beyond the limits of the current way of managing public health. There are still important Gordian knots to untie to move the model forward: firstly, the role of political contexts, where discourse is not enough, but commitments have to be made to maintain the will of the highest authority at each level of government. So far, there is no comprehensive strategy in Germany that encompasses health at all levels and in all policy areas; for this, the different political parties and actors must familiarise themselves with a salutogenic understanding of health and, from there, negotiate the conflicting interests [24]. The increased pressure caused by the COVID-19 pandemic and climate change provide an opportunity to develop this proposal.

Secondly, the role of cultural contexts. Health in all policy areas is part of the shift from a biomedical model to one that addresses the underlying determinants of health. underlying determinants of health; segmentation and fragmentation of actors and responsibilities, heterogeneity of interests and insufficient coordination between levels of action and actors persist in Germany [25]. Conceptual sustainability needs to be strengthened in public institutions where conflicts of interest are created and aggravated, through multi-sectoral assessments by health experts with experience in other fields in order to provide a health-promoting perspective. All existing potentials in all sectors must also be brought together and strengthened through targeted policies and properly organised human resource development processes that go well beyond non-binding voluntary commitments.

Thirdly, financial sustainability to maintain structures and processes. The Law on Strengthening Health Promotion and Prevention (Prevention Law) [26], passed in 2015, is primarily oriented towards compulsory health insurance as a payer and excludes other sources of funding. This limited structure does not do justice to the claim of a bottomup approach to understand the creation of healthy living conditions as a comprehensive task and to include all health stakeholders in a binding way as far as possible. Reforms to the legal instrument should privilege health promotion in the municipalities and particularly encourage deliberative planning between citizens and the mayors.

Last but not least, it is about the role of citizen participation in the context in which different actors pursue common strategies to achieve a more level playing field. One of the objectives of participation is to open up political and organisational decision-making processes to citizens.

This should lead to the inclusion of additional competences and ideas, to open competition and ultimately to greater legitimacy of the results. In Germany, many municipal projects still lack adequate participation in decision-making by the people who will benefit from them [27]. Therefore, there is a need to develop deliberative mechanisms and legal frameworks that make it easier for people to: identify their interests and values, contribute ideas and acquire a greater degree of autonomy to design health/quality of life action plans together with the government [28,29].

With these considerations in mind, policy makers must be prepared to transform existing regulations into a new legal framework that assigns health work in all policies as a shared responsibility of the health sector together with nonhealth institutions and organised communities. In addition, municipalities, Länder and central level ministries must incorporate legal provisions to operationalise key strategies, including executive orders or directives, resolutions and regulations [30] that promote the participation of all sectors to ensure that the structural change proposed in the new legal framework is sustained over time, even if there are changes in leadership and personnel.

\section{References}

1. WHO Regional Office for Europe (2008) The Tallinn Charter: health systems for health and wealth.

2. WHO European Ministerial Conference on Health Systems, Estonia World Health Organization (2014) The Helsinki Statement on health in all policies. Health Promot Int 29(S1): S17-S19.

3. Die Bundesregierung (2020) Strategie der Bundesregierung zur globalen Gesundheit. Verantwortung-Innovation-Partnerschaft: Globale Gesundheit gemeinsam gestalten. Bundesministerium für Gesundheit, Berlin, DE, pp: 44.

4. Zukunftsforum Public Health (2021) Eckpunkte einer Public-Health-Strategie für Deutschland. Zukunftsforum Public Health, Berlin, DE, pp: 66.

5. Mandl Stangl J (2021) Health in All Policies: Management Model for the Comprehensive Transformation of the System. J Qual Healthcare 4(2): 000217.

6. World Health Organization (2015) Health in all policies: training manual. Vivien Stone (Editor), World Health Organization, Geneva, Switzerland, pp: 250.

7. Dragano N, Conte A (2020) Health in All Policies und 
gesundheitliche Chancengleichheit: COVID-19 als Fallstudie. Public Health Forum 28(3): 185-187.

8. Geene R, Kurth BM, Matusall S (2020) Health in All Policies-Entwicklungen, Schwerpunkte und Umsetzungsstrategien für Deutschland. Gesundheitswesen 82(07): e72-e76.

9. Kickbusch I, Lin V (2017) Progressing the Sustainable Development Goals through Health in All Policies: Case studies from around the world. Government of South Australia, Adelaide, pp: 204.

10. Greer S, Maresso A (2012) Intersectoral problem solving by Interdepartmental Units and Committees. Eurohealth OBSERVER 18(4): 11-14.

11. McQueen D, Wismar M, Lin V, Jones CM, Davies (2012) Intersectoral governance for Health in All Policies. Structures, actions and experience. WHO/EUR on behalf of the European Observatory on Health Systems and Policies, Copenhage, Denmark, pp: 221.

12. Kickbusch I, Behrend $T$ (2013) Implementing a Health 2020 vision: governance for health in the 21st century. Making it happen. WHO/EUR, Copenhage, Denmark, pp: 92.

13. Clavier C (2016) Implementing health in all policies-time and ideas matter too! Comment on Understanding the role of public administration in implementing action on the social determinants of health and health inequities. Int J Health Policy Manag 5(10): 609-610.

14. De Leeuw E, Green G, Spanswick L, Palmer N (2015) Policymaking in European healthy cities. Health Promot Int 30(S1): i18-i31.

15. Ndumbe Eyoh S, Moffatt H (2013) Intersectoral action for health equity: a rapid systematic review. BMC Public Health, 1056.

16. Kickbusch I, Gleicher D (2012) Governance for health in the 21st century. WHO/EUR, Copenhagen, Denmark, pp: 128.

17. Hoeijmakers M, De Leeuw E, Kenis E (2007) Local health policy development processes in the Netherlands: an expanded toolbox for health promotion. Health Promotion International 22(2): 112-121.

18. World Health Organization (2015) Health in all policies: training manual. Vivien Stone (Editor), World Health Organization, Geneva, Switzerland, pp: 250.

19. Mauti J, Gautier L, De Neve JW (2019) Kenya's Health in All Policies strategy: a policy analysis using Kingdon's multiple streams. Health Research Policy and Systems 17(15): 1-12.

20. Commission to Build a Healthier America (2011) Health Impact Assessment: A Tool for Promoting Health in All Policies.ISSUE BRIEF \#11 Robert Wood Johnson Foundation, Washington, DC, pp: 13.

21. Kim HY (2006) Assessing the role of social capital in the community development field: a multi-level analysis. The University of Georgia, Athens, USA, pp: 189.

22. Weth C (2020) Das Gesunde Städte-Netzwerk. In: Böhm K, Bräunling S, Geene R, Köckler H, et al. (Eds.), Gesundheit als gesamtgesellschaftliche Aufgabe. Springer VS, Wiesbaden, DE, pp: 305-311.

23. Pinto AD, Molnar A, Shankardass K (2015) Economic considerations and health in all policies initiatives: evidence from interviews with key informants in Sweden, Quebec and South Australia. BMC Public Health 171.

24. Böhm K, Lahn J, Köckler H, Geene R, Bräunling S (2020) Health in all policies: ¿Wo stehen wir und was braucht es für die weitere Entwicklung?. Gesundheit als gesamtgesellschaftliche Aufgabe. Springer VS, Wiesbaden, DE, pp: 427-434.

25. KabaSchönsteinL,TrojanA(2018)Gesundheitsförderung 5: Deutschland. Bundeszentrale für gesundheitliche Aufklärung (BZgA).

26. Bundesgesetzblatt (2015) Gesetz zur Stärkung der Gesundheitsförderung und der Prävention. Teil I $\mathrm{N}^{\circ} 31$, ausgegeben zu Bonn am 24. 07. 2015. Bundesanzeiger Verlag, Köln, DE, pp: 12.

27. Hartung S, Wright MT (2015) Partizipation in der Gesundheitsförderung: Weiter, aber noch nicht am Ziel. Impu!se 88: 3-4.

28. De Leeuw E, Harris Roxas B (2020) Crafting health promotion: from Ottawa to beyond Shanghai. (2016) Environnement, Risques \& Santé 15(6): 461-464.

29. Mandl Stangl J (2021) The Time for more Deliberative Citizen Participation has come. J Qual Healthcare 4(5): 000243.

30. Johnson R, Wooten H (2015) From Start to Finish: How to Permanently Improve Government through Health in All Policies. ChangeLab Solutions, Oakland, USA, pp: 42. 